УДК 811.124’01

DOI https://doi.org/10.26661/2414-9594-2020-2-16

\title{
ІМЕННИКОВІ ФРАЗИ 3 «DIES» НА МАТЕРІАЛІ КОМЕДІЙ ТІТА МАКЦІЯ ПЛАВТА
}

\author{
Панчишин Н. 3. \\ асистент кафедри класичної філології \\ Львівський начіональний університет імені Івана Франка \\ вул. Університетська, 1, Львів, Україна \\ orcid.org/0000-0001-6348-2949 \\ zjanysja@ukr.net
}

Ключові слова: іменникова фраза, ядро-іменник, бінарний, полікомпонентний, регресивний, прогресивний, рамкова структура.
Стаття присвячена дослідженню іменникових фраз, які були і $є$ темою багатьох зарубіжних та українських лінгвістичних праць. У наукових роботах розглядаються ієрархічні відношення в структурі іменникових фраз, закономірності їх розташування, класифікації препозитивних і постпозитивних компонентів. Лінгвісти також аналізують різні аспекти іменникових фраз у порівнянні двох мов, у різних мовних стилях.

Однак ще не всі аспекти іменникових фраз висвітлено, немає єдиного підходу до аналізу цього питання. Тому дослідження функціонування, взаємодії семантики та синтаксису на рівні словосполучення, особливо на матеріалі латинських текстів, є актуальним і заслуговує на грунтовне вивчення.

Мета роботи полягає в дослідженні структури іменникових фраз із часовим словом «DIES»-«день», яке є ядром лексико-семантичної групи частин дня, i їх функціонування в комедіях Плавта.

Обсяг іменникових фраз, їх морфологічний склад, аранжування компонентів і зв'язок між ними є частинами дослідження структури іменникової фрази. Структура іменникових фраз може бути розкрита краще 3 погляду функціонування мовних одиниць.

Аналіз синтагматичних зв'язків в іменникових фразах 3 «DIES» - «день» указує на те, що це слово сполучається з прикметниками 3 указівкою на цілковите охоплення дією часового відрізка, тривалості часового відрізка, співвіднесеність із певними (точними) відрізками часу, послідовність часових відрізків. Також це ядро-іменник уживається із займенниками, займенниковими прикметниками та кількісними числівниками. Важливим аспектом дослідження $є$ сполучуваність іменника «DIES» 3 прийменниками. У результаті дослідження функціонування іменникових фраз з'ясувалося, що Плавт у текстах комедій використовував такі структури іменникових фраз: бінарні регресивні, бінарні прогресивні, полікомпонентні регресивні та полікомпонентні рамкові іменникові фрази.

Найбільш частотними виявилися регресивні іменникові фрази, а найменш частотними - прогресивні. Полікомпонентні фрази переважно складаються 3 трьох компонентів. Найуживанішими компонентами досліджуваних фраз є вказівні займенники, прикметники та прийменники. Перспективним для подальшого дослідження вбачається вивчення іменникових фраз у творах різних стилів, а також аналіз функційних, структурних і семантичних особливостей іменникових фраз з іншими ядрами-іменниками на позначення часу. 


\title{
NOUN PHRASES WITH "DIES" ON THE MATERIAL OF TITUS MACCIUS PLAUTUS'S COMEDIES
}

\author{
Panchyshyn N. Z. \\ Assistant at the Department of Classical Philology \\ Ivan Franko National University of Lviv \\ University str., 1, Lviv, Ukraine \\ orcid.org/0000-0001-6348-2949 \\ zjanysja@ukr.net
}

Key words: noun phrase, corenoun, binary, multicomponent, regressive, progressive, frame structure.
This article deals with the study of noun phrases, which were and are the topic of many foreign and Ukrainian linguistic works. In scientific works hierarchical relations in the structure of noun phrases, regularities of their arrangement, classification of prepositional and postpositive components are considered. Linguists also analyze different aspects of noun phrases by comparing two languages, in different language styles.

However, not all aspects of noun phrases have been covered yet and there is no single approach to analyzing this issue. Therefore, the study of the functioning, interaction of semantics and syntax at the level of phrases, especially on the material of Latin texts, is relevant and deserves a thorough study.

The aim of the work is to study the structure of noun phrases with the temporal word "DIES"-"day", which is the core of the lexical-semantic group of the day parts and their functioning in Plautus's comedies.

The volume of noun phrases, their morphological composition, arrangement of components and the relationship between them are the part of the noun phrase structure study. The structure of noun phrases can be better revealed in terms of the functioning of language units.

Analysis of syntagmatic connections in noun phrases with "DIES"-"day", indicates that the word is combined with adjectives with an indication of the full coverage of the time interval action, the time interval duration, the correlation with certain (exact) time intervals, the sequence of time segments. Also, this core-noun is used with pronouns, pronoun adjectives and numerals. An important aspect of the study is the compatibility of the noun dies with prepositions.

As a result of research on the functioning of noun phrases, it became clear that Plautus used the following structures of noun phrases in his comedies: binary regressive, binary progressive, multicomponent regressive and multicomponent frame noun phrases.

The most frequent were regressive noun phrases, and the least frequent progressive. Multicomponent phrases mainly consist of three components. The most commonly used components of the studied phrases are indicative pronouns, adjectives and prepositions.

The study of noun phrases in works of different styles, as well as the analysis of their functional, structural and semantic features with other core-nouns to denote time is considered promising for further research.
У сучасному мовознавстві діапазон досліджень значно розширився завдяки теоретичному та практичному інтересу до вивчення особливостей і функціонування мовних одиниць.

Дослідженню іменникових фраз приділяється багато уваги як у зарубіжній, так і в українській лінгвістиці. Вагоме місце у вивченні цього питання посідає теорія О. Єсперсена, яка дала змогу побачити ієрархію синтаксичних відношень: головне слово (ядро) має першочергове значення, уточнюється другим словом, яке підпорядковує собі третє [16, с. 96]. Дж.Н. Гук та Е. Метьюз теж присвятили праці ієрархічним відношенням, однак уже на синтаксичному рівні [14]. Такі лінгвісти, як А. Хілл [13], С. Четмен [12], досліджували закономірності розташування елементів іменникових фраз, здійснили класифікацію препозитивних компонентів. Дж.А. Хаф [15] характеризує як 
препозитивні, так і постпозитивні конструкції. Окрім дослідження морфологічних і семантичних зв'язків, між компонентами іменникових фраз деякі вчені, такі як А. Хілл, С. Четмет, Ч. Фріз та Г. Серенсен, також аналізують їх обсяг. Стосовно функції іменникових фраз у реченні найпоширенішим серед мовознавців є погляд О. Єсперсена щодо відмінності рангів усередині словосполучення й усередині речення [16, с. 90].

В українській і російській лінгвістиці дослідження іменникових фраз здійснюється на базі багатьох мов такими мовознавцями, як В. Бурлакова, І. Бойцова, Е. Тернова, В. Гак, Ц. Левіна, Н. Варламова, А. Мизак, І. Калиновська, І. Гульт, А. Левицький, I. Фролова, Т. Яворська та ін. Лінгвісти досліджують різні аспекти іменникових фраз у порівнянні двох мов, у різних мовних стилях. Низку праць присвячено прийменниковим іменниковим фразам, особливостям трансформацій полікомпонентних атрибутивних іменникових фраз, проблемі валентності іменників у реченні та в іменникових фразах.

Аналіз лінгвістичної літератури показує, що ще не всі аспекти іменникових фраз висвітлено, немає єдиного підходу до аналізу цього питання. Тому дослідження функціонування, взаємодії семантики та синтаксису на рівні словосполучення, особливо на матеріалі латинських текстів, $є$ актуальним і заслуговує на грунтовне вивчення.

Об'єктом дослідження стали іменникові фрази зі словом «DIES»- «день», яке належить до темпоральної лексики на позначення частин дня.

Предметом статті є структурні та функційні властивості іменника «DIES». Аналіз парадигматичних особливостей лексичних одиниць, доповнений на рівні синтагматики, дає можливість установити певні властивості мовних елементів щодо один до одного, виявити залежності між системою одиниць мови та їх функціонуванням у тексті.

Мета роботи полягає в дослідженні структури іменникових фраз із часовим словом «DIES»«день», яке є ядром лексико-семантичної групи частин дня, і їх функціонування в комедіях Тіта Макція Плавта.

Іменникова фраза - це синтаксична конструкція, до складу якої входять головний та один чи декілька залежних компонентів, причому головним компонентом-ядром $€$ іменник $[8$, с. 9].

Термін «іменникова фраза» відрізняється від терміна «словосполучення», яке включає поєднання двох повнозначних слів, тим, що передбачає в складі наявність службових слів (у латинській мові це прийменники).

Аналіз структури іменникової фрази передбачає визначення іiї обсягу, морфологічного складу, аранжування компонентів і зв'язок між ними $[1$, с. 3$]$.
Під обсягом мається на увазі кількість компонентів. Іменникові фрази бувають бінарними та полікомпонентними. Бінарна фраза - це сполучення ядра-іменника 3 одним залежним компонентом, полікомпонентна складається 3 ядра-іменника та двох чи більше компонентів. Аранжуванням компонентів називають поділ іменникових фраз на регресивні, прогресивні та рамкові. Терміни «регресивна» й «прогресивна» іменникова фраза запозичено з праці В. Інгве [7]. У прогресивних фразах залежні компоненти розташовані справа від ядра-іменника, а в регресивних - зліва. Е. Мороховська вводить термін «рамкова структура», під яким розуміє двостороннє розташування залежних компонентів щодо ядра [10].

Аналіз структури іменникових фраз передбачає також визначення інвентарю моделі іменникової фрази, під яким розуміють відображення послідовності класу слів. У моделі використовуються такі позначення: S (substantivum) - ядро-іменник, Adi (Adiectivum) - прикметник, Pron (Pronomen) займенник, AP (Adiectivum pronominale) - займенниковий прикметник, $\operatorname{Pr}$ (Praepositio) - прийменник, NC (Numerale cardinale) - кількісний числівник, NO (Numerale ordinale) - порядковий числівник.

Багатоаспектність структури іменникових фраз може бути розкрита краще з урахуванням ïx функційних особливостей, бо будь-яке лінгвістичне явище може вважатися дослідженим тоді, коли враховуються не лише системні, а також функційні характеристики. «Функційний підхід дає можливість дослідити реалізацію факторів мови в мовленні, виявити суттєві закономірності вживання лексичних одиниць щодо їх конкретних функційних властивостей» [5, с. 12].

Складні взаємовідношення між функціюванням мовних одиниць i ïx структурою та семантикою відображають синтагматичні й парадигматичні властивості іменникових фраз. Синтагматичні відношення визначають можливості ядра-іменника, яке є граматично та семантично домінуючим компонентом іменникових фраз, поєднуватися з іншими словами. Парадигматичні ознаки відображаються в розподілі іменникових фраз як синтаксичних одиниць щодо інших компонентів речення.

Аналіз синтагматичних зв'язків в іменникових фразах із «DIES» - «день» дає нам змогу виділити такі лексичні та лексико-граматичні класи прикметників зі значеннями: 1) слова 3 указівкою на цілковите охоплення дією часового відрізка: totus, a, ит - весь, иілий: Nam dies totos aput portum servus unus adsidet (Pl. St. 152) - «Бо всі дні раб один сидить біля порту»; 2) тривалості часового відрізка: continuиs, a, um - тривалий, безперервний: Verum ubi dies decem continuos sit... (Pl. Mil. 743) - «Коли підряд мине 10 днів...»; 
3) співвіднесеність 3 певними (точними) відрізками часу: natalis, $e-$ пов'язаний із днем народження, festus, a, ит - святковий: Certumst mi hunc emortualem facere ex natali die (Pl. Ps. 1237) «Доведеться мені з дня народження зробити день смерті»; Ut opperiare hos sex dies festos modo... (P1. Ps. 321) - «Щоб ти притримав це в тайні ще днів святкових шість»; 4) послідовність часових відрізків 3 підкласами: а) прикметники 3 указівкою на віднесеність до певного моменту в часі: crastinus, a, ит - завтрашній, suтmиs, а, ит - останній, hesternus, a, ит-учорашній: Neque Athenas advenit umquam ante hesternum diem (Pl. Ps. 731) - «Узагалі не був в Афінах до вчорашнього дня»; ... hoc die crastini quom erus resciverit (Pl. Most. 881) - «... завтра ж господар дізнається»; б) порядкові числівники: primus, a, um-перший; tertius, a, um-mретіŭ mомп: Cocus ille nundinalest, in nonum diem solet ire coctum (Pl. Aul. 324) - «Повар він поминальний, на дев'ятий день зазвичай приходить готувати»; в) 3 нечітко визначеною протяжністю: multus, $a$, uт - багато, численний; conplusculi, ae, a-доволі численні; раисиь, а, ит - незначний, декілька: Nunc intervallum iam hos dies multos fuit (Pl. Rud. $137)$ - «Зараз же перерва була протягом цих багатьох днів»; Non hercle, adulescens, iam hos dies conplusculos quemquam istic vidi sacruficare (Pl. Rud. 131-132) - «Клянусь, юначе, нікого не бачив, хто б приносив жертви вже протягом багатьох днів»; ... dicat me in diebus pauculis (P1. Truc. 643) - «... заговорить зі мною через декілька днів».

Окрім розглянутих вище прикметників, іменник «DIES» також уживається 3 указівними займенниками (hic, haec, hoc; is, ea, id-ueü, uя, uе тощо), неозначеним займенником (aliquis, aliquid - будb-який, $a, e)$ та займенниковими прикметниками (alius, a, ud-iншuй, другий; alter, a, ит - другий; ипиs, а, ит - один, один і той самий тощо), які не змінюють лексичного значення слова, а лише уточнюють його: Illo die inpransus fui (Pl. Am. 254) - «У цей день без обіду був»; ... ruri sum ego unos sex dies (Pl. Trin. 166) - «У селі пробуду лише шість днів»; Eodem die ubi viduli sies potitus (Pl. Rud. 1337) - «У той самий день, коли ти отримаєш усе добро»; Immo amabo ut hos dies aliquos sinas eum esse apud me (Pl. Truc. 872-873) - «Я б хотів, щоб ти залишив його в мене на ці декілька днів); Numquam ecastor ullo die risi (P1. Cas. 858) - «Клянусь Кастором, ще ніколи жодного дня я так не сміялася».

Непоодиноким є також поєднання «DIES» із кількісними числівниками, які лише вказують на кількість і не впливають на значення слова: ... vino viginti dies ut careat (Pl. As. 801) - «Щоб він був позбавлений вина на 20 днів».

Важливим аспектом дослідження функціонування іменника «DIES» $\epsilon$ його сполучуваність із прийменниками. Досліджуваний іменник сполучається 3 часовими прийменниками, що трансформувалися 3 просторових. Як висловився В. Виноградов, «часові значення суміщаються 3 просторовими 1 розвиваються на їх основі» [4, с. 538].

У комедіях Плавта трапляються такі прийменники в поєднанні 3 «DIES»: ante - перед, $\partial o:$... neque ego istuc nomen umquam audivi ante hunc diem (Pl. Capt. 634) - «Я ніколи не чув це ім'я до цього дня»; intra - протягом, упродовж: ... usque omnium subegit solus intra viginti dies (P1. Curc. 448) - «За 20 днів підкорив усе це один»; post - niсля, на: Si situlam cepero, numquam edepol tu mihi divini creduis post hunc diem (Pl. Am. 671-672) - «Якщо відро візьму, то, клянусь, ніколи ти мені не довірятимеш після цього дня ...»; inter - niд час, між, протягом, упродовж: Inter tot dies quidem hercle iam aliquid actum oportuit (Pl. Truc. 510) - «За стільки днів, клянусь, варто б йому зробити щось»; de - в, nid час, протягом: Ecqua pars orationis de die dabitur mihi? (Pl. As. 518) - «Чи даси мені вимовити хоч слівце за день?»; ex(e) - 3, із, після, услід за: Res serias omnis extollo ex hoc die in alium diem (Pl. Poen. 500) - «Yci справи я відкладаю із цього дня на інший день»; in-на (який час?, як довго?), протягом (якого часу), за (скільки часу): Nam illum confido domum in his diebus me reconciliassere (Pl. Capt. 167) - «Оскільки я сподіваюся повернути його додому иими днями».

У результаті дослідження функціонування іменникових фраз з'ясувалося, що Плавт у текстах комедій використовував такі структури іменникових фраз: 1) бінарні регресивні іменникові $\boldsymbol{\phi p a з и , ~ я к і ~ о п и с у ю т ь с я ~ т а к и м и ~ м о д е л я м и : ~ P r o n ~}+\mathrm{N}$ (illo die, eodem die), Praep $+\mathrm{N}$ (in die, de die), $\mathrm{NC}+\mathrm{N}$ (viginti dies), Adi $+\mathrm{N}$ (natali die, longa dies); 2) бінарні прогресивні: N+Adi (dies summa, dies paucos), N+AP (dies totos), N+NO (die septumei); 3) полікомпонентні регресивні: $\mathrm{Praep}+\operatorname{Pron}+\mathrm{N}$ (post hunc diem, in his diebus); $\mathrm{AP}+\mathrm{NC}+\mathrm{N}$ (unos sex dies), Adi + Adi $+\mathrm{N}$ (praestituta summa dies), Praep+Adi+N (ante hesternum diem, ex natali die), Pron $+\mathrm{NO}+\mathrm{N}$ (hoc uno die), Pron + Adi $+\mathrm{N}$ (suo festo die), Praep $+\mathrm{NO}+\mathrm{N}$ (in nonum diem), Preap $+\mathrm{AP}+\mathrm{N}$ (in alium diem), Praep $+\mathrm{NC}+\mathrm{N}$ (intra viginti dies); 4) полікомпонентні рамкові: Pron+N+Adi (hos dies conplusculos, hos dies multos, hoc die crastini), Pron $+\mathrm{NC}+\mathrm{N}+\mathrm{Adi}$ (hos sex dies festos), Praep+N+Adi (in diebus pauculis), Pron $+\mathrm{N}+$ Pron (hos dies aliquos).

Плавт у комедіях не використовує полікомпонентні прогресивні іменникові фрази 3 «DIES».

Найбільш частотними виявилися регресивні іменникові фрази, а найменш частотними - прогресивні. Полікомпонентні фрази переважно складаються 3 трьох компонентів. 
Найуживанішими компонентами досліджуваних фраз є вказівні займенники, прикметники та прийменники. Максимальне функційне навантаження в мовленні автора несуть моделі: Pron $+\mathrm{N}$, Praep + Pron $+\mathrm{N}$

У межах одного дослідження складно охопити все коло питань, пов'язаних із цією проблемою.
Перспективним убачається розширення рамок дослідження за рахунок вивчення іменникових фраз у творах різних стилів, а також аналіз функційних, структурних і семантичних особливостей іменникових фраз з іншими ядрами-іменниками, які утворюють лексичну групу іменників на позначення часу.

\author{
Pl. - Plautus \\ Am. - Amphitriuo \\ As. - Asinaria \\ Aul. - Aulularia \\ Capt. - Captivi \\ Epid. - Epidicus \\ Mil. - Miles Gloriosus \\ Mos. - Mostellaria \\ Poen. - Poenulus \\ Ps. - Pseudolus \\ Rud. - Rudens \\ St. - Stichus \\ Trin. - Trinummus \\ Truc. - Truculentus
}

\title{
ЛІТЕРАТУРА
}

1. Бедер И.Я. Структурная емкость группы существительного в современном английском языке : автореф. дисс. ... канд. филол. наук : 13.00.02. Ленинград, 1974. 21 с.

2. Бедринець Л.Г. Структура тричленних номінативних словосполучень та характер відношень їх компонентів. Питання романо-германської філологї̈ та методики викладання іноземних мов. Київ : Радянська школа, 1974. Вип. 1. С. 71-75.

3. Бурлакова В.В. Основы структуры словосочетания в современном английском языке. Москва : Просвещение, 1984. 144 с.

4. Виноградов В.В. Русский язык. Грамматическое учение о слове. Москва : Учпедгиз, 1972. 614 с.

5. Гак В.Г. К проблеме семантической синтагматики. Проблемы структурной лингвистики. Москва : Наука, 1972. С. 367-395.

6. Гульт I.М. Функціонально-семантичний аналіз структури бінарних регресивних іменникових фраз у текстах художньої прози (на матеріалі англійської мови). Слов'янський вісник : збірник наукових праць. Рівне, 2003. Рівне, 2003. Вип. 4 : Філологічні науки. С. 156-161.

7. Ингве В. Гипотеза глубины. Новое в лингвистике. Москва : Прогресс, 1965. Вып. IV. С. 126-138.

8. Калиновська I.M. Структурні й семантичні особливості іменникових фраз в англомовній художній прозі : монографія / Волин. нац. ун-т ім. Л. Українки. Луцьк : Вежа, 2009. 209 с.

9. Левицький А.Е. Функціональний підхід до аналізу системи номінативних одиниць сучасної англійської мови. Вісник Харківського національного університету ім. В.Н. Каразіна. 2000. № 471. С. 137-143.

10. Мороховська Е.Я. Основи граматики англійської мови: Теорія і практика : навчальний посібник. Київ : Вища школа, 1993. 472 с.

11. Цвяк Л.В. Прикметники, що позначають освітлення в сучасній німецькій мові (дистрибутивно-статистичний аналіз) : автореф. дис. ... канд. філол. наук : 10.02.04 / Одес. нац. ун-т ім. І.І. Мечникова. Одеса, 2001. 20 c.

12. Chatmen S. Pre-adjectives in the English Nominal Phrase. American speech.1960.Vol. 35. № 1. P 36-59.

13. Hill A.A. Introduction to linguistic structures: from sound to sentence in English. N.Y. : Harcout, Brace and World, 1958. $496 \mathrm{p}$.

14. Hook J.N., Mathews E.G. Modern American Grammar and Usage. N.Y. : Holt, Rinehart and Winston, 1956. $214 \mathrm{p}$.

15. Hough G.A. Structures of Modification in Contemporary American English. L. : The Hauge Mouton, $1971.218 \mathrm{p}$.

16. Jespersen O. The Philosophy of Grammar. University of Chicago Press, 1992. 269 p.

17. URL: https://www.thelatinlibrary.com/plautus.html. 


\section{REFERENSES}

1. Beder, I. Ya. (1974) Strukturnaja emkost gruppy sushhestvitelnogo v sovremennom anglijskom jazyke [Structural capacity of a noun group in modern English]. Extended abstract of candidates thesis. Leningrad [in Russian].

2. Bedrynets, L. G. (1974) Struktura trychlennykh nominatyvnykh slovospoluchen ta kharakter vidnoshen yikh komponentiv [The structure of three-membered nominative phrases and the nature of the relations of their components]. Questions of Romano-Germanic philology and methods of teaching foreign languages, 1, 71-75 [in Ukrainian].

3. Burlakova, V.V.(1984) Osnovy struktury slovosochetaniya $v$ sovremennom anglijskom yazyke [Fundamentals of the structure of a phrase in modern English]. Moskva : Prosveshchenije [in Russian].

4. Vinogradov, V.V.(1972) Russkij yazyk. Grammaticheskoe uchenie o slove [Russian language. Grammar teaching about the word]. Moskva: Uchpedgiz [in Russian].

5. Hak, V.H.(1972) K probleme semanticheskoj sintagmatiki [On the problem of semantic syntagmatics]. Structural linguistics problems (pp. 367-395). Moskva : Nauka [in Russian].

6. Hult, I.M. (2003) Funkcionalno-semantychnyj analiz struktury binarnyx regresyvnyx imennykovyx fraz u tekstax xudozhnoyi prozy (na materiali anglijskoyi movy) [Functional-semantic analysis of the structure of binary regressive noun phrases in texts of fiction (on the material of the English language)]. Slovjanskyj visnyk, 4, 156-161 [in Ukrainian].

7. Ingve, V. (1965) Gipoteza glubiny [Depth hypothesis]. New in linguistics, 4, 126-138 [in Russian].

8. Kalynovska, I.M. (2009) Strukturni j semantychni osoblyvosti imennykovyx fraz v anglomovnij xudozhnij prozi [Structural and semantic features of noun phrases in English fiction]. Lutsk : Veza [in Ukrainian].

9. Levytskyj, A.E. (2000) Funkcionalnyj pidxid do analizu systemy nominatyvnyx odynycz suchasnoyi anglijskoyi movy [Functional approach to the analysis of the system of nominative units of modern English]. Visnyk Kharkivskoho natsionalnoho universytetu im. V. N. Karazina, 471, 137-143 [in Ukrainian].

10. Morohovska, E. Ya. (1993) Fundamentals of English grammar: Theory and practice. Kyiv : Vyshcha shkola [in Ukrainian].

11. Tsviak, L.V.(2001)Prykmetnyky, shho poznachayut osvitlennya v suchasnij nimeczkij movi(dystrybutyvnostatystychnyj analiz) [Adjectives denoting lighting in modern German (distributive-statistical analysis)]. Extended abstract of candidates thesis. Odesa [in Ukrainian].

12. Chatmen, S. (1960) Pre-adjectives in the English Nominal Phrase. American speech,35 (1), 36-59.

13. Hill, A.A. (1958) Introduction to linguistic structures: from sound to sentence in English. N.Y. : Harcout, Brace and World.

14. Hook, J.N.\& Mathews, E.G. (1956) Modern American Grammar and Usage. N.Y.: Holt, Rinehart and Winston.

15. Hough, G.A. (1971) Structures of Modification in Contemporary American English. London: The Hauge Mouton.

16. Jespersen, O. (1992) The Philosophy of Grammar. Chicago : University of Chicago Press.

17. URL: https://www.thelatinlibrary.com/plautus.html. 